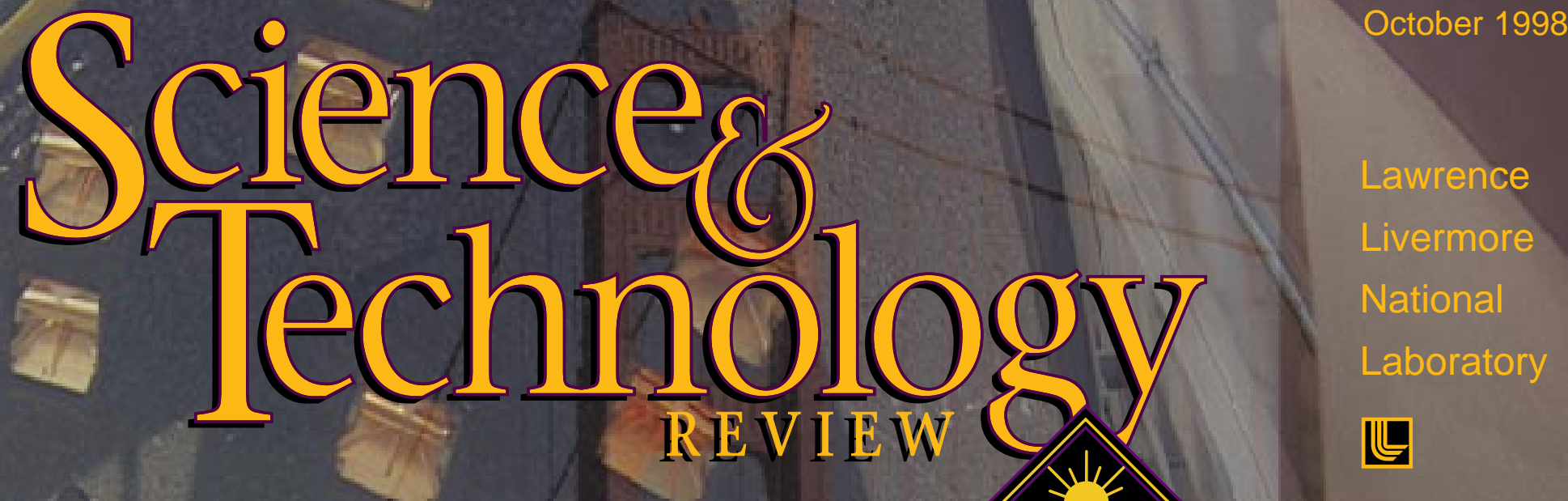

Light Lock Optical Security System

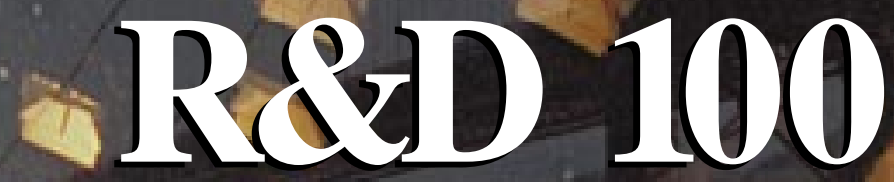

7

HERMES Bridge Inspection System

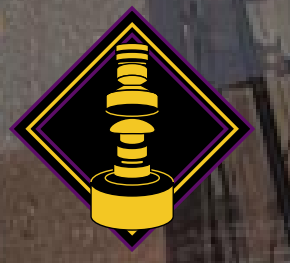

\title{
AWAIDDS
}

Optical/-Dental Imaging Systêm
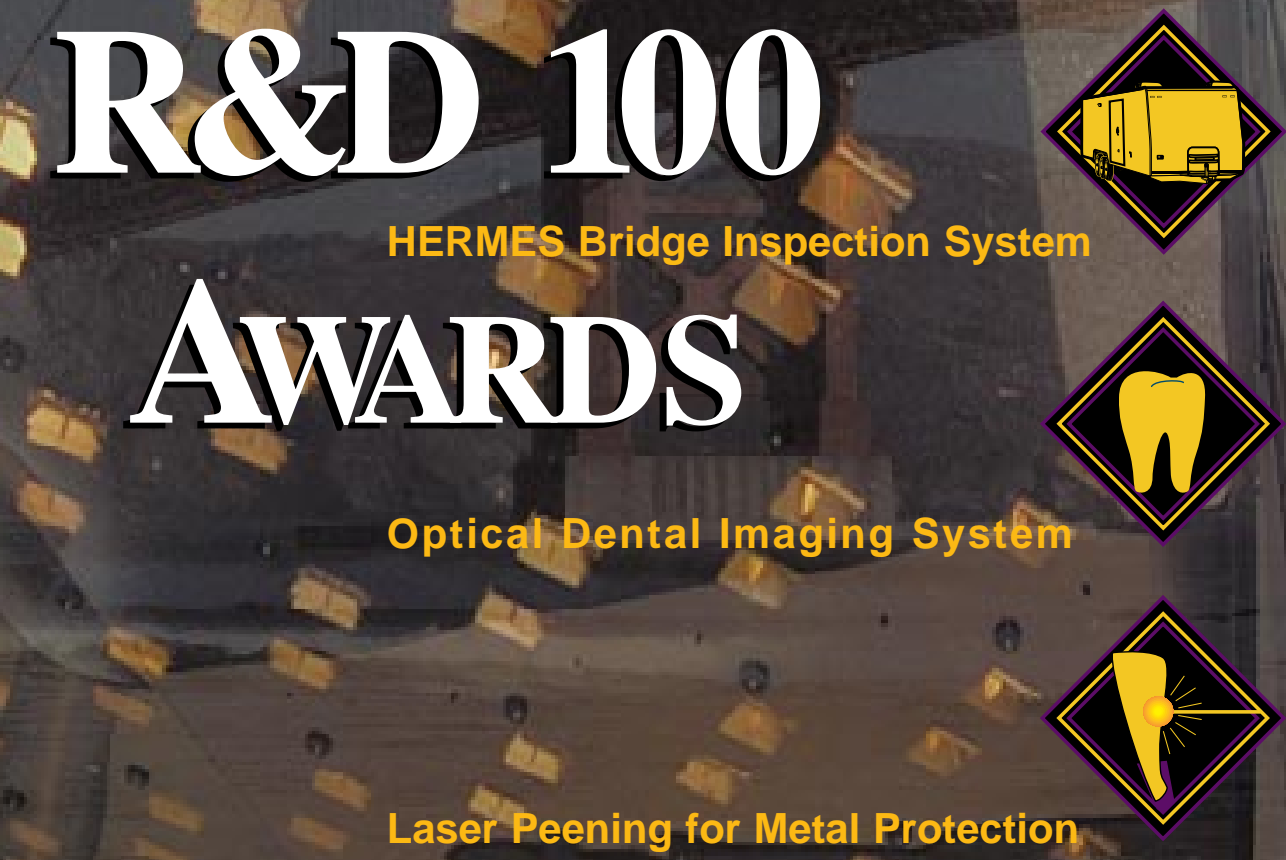

Laser Peening for Metal Protection

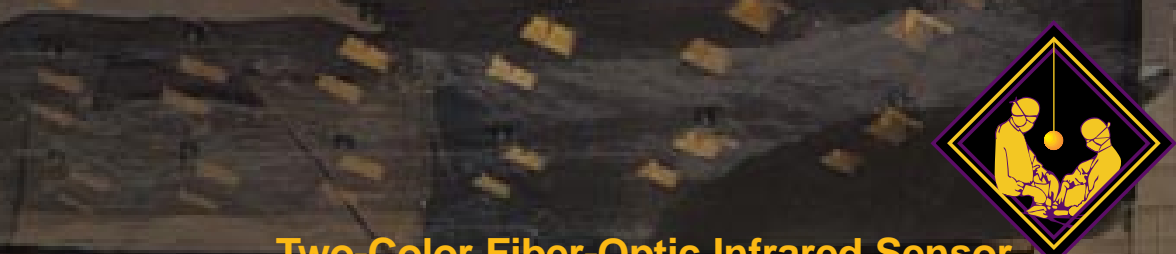

Two-Color Fiber-Optic Infrared Sensor-
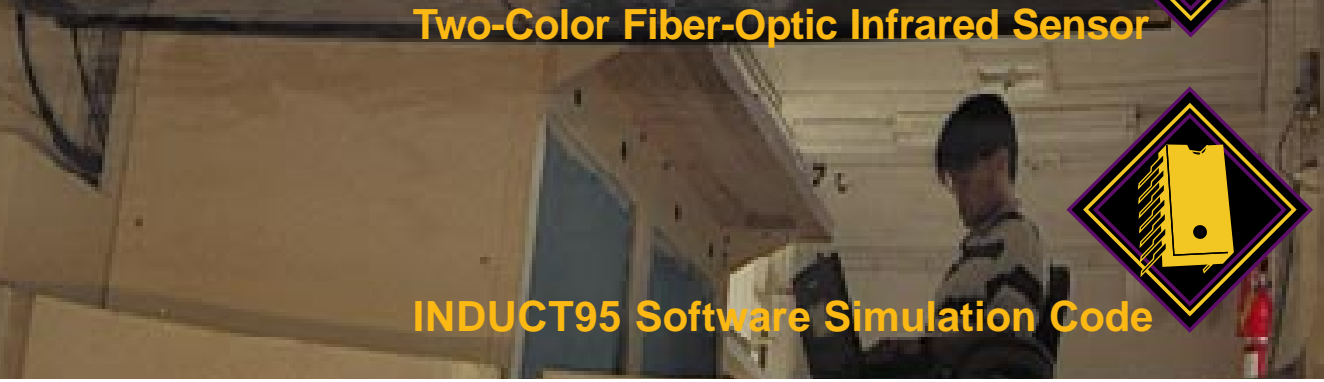


\section{About the Cover}

Superimposed against the familiar Golden Gate Bridge, Livermore's HERMES Bridge Inspector demonstrated again this summer its capability in detecting and mapping bridge deck defects. The HERMES trailer, containing 64 high-speed impulse radar modules, gathers information as it is pulled across bridge decks at 55 miles per hour. HERMES is one of seven Livermore inventions that won R\&D 100 Awards, $R \& D$ Magazine's top technological achievements of 1998. The award-winning inventions are described in this issue, beginning on p. 4.

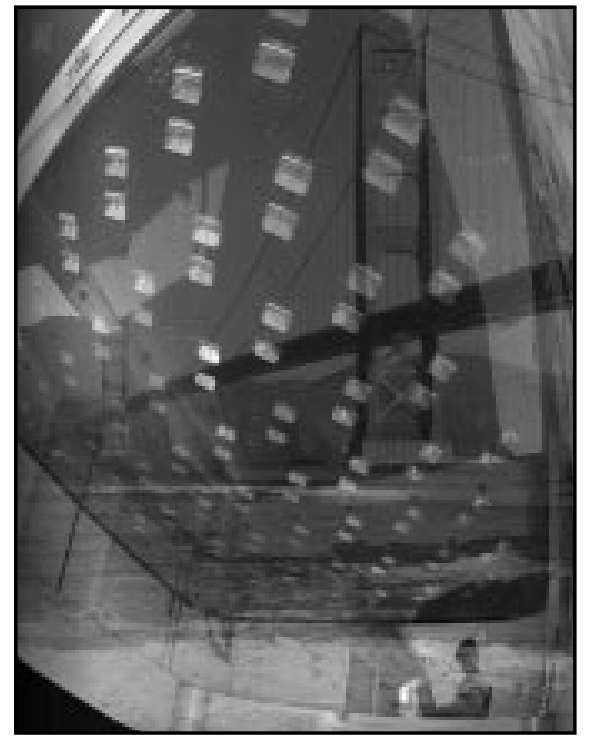

\section{About the Review}

Lawrence Livermore National Laboratory is operated by the University of California for the Department of Energy. At Livermore, we focus science and technology on assuring our nation's security. We also apply that expertise to solve other important national problems in energy, bioscience, and the environment. Science \& Technology Review is published ten times a year to communicate, to a broad audience, the Laboratory's scientific and technological accomplishments in fulfilling its primary missions. The publication's goal is to help readers understand these accomplishments and appreciate their value to the individual citizen, the nation, and the world.

Please address any correspondence (including name and address changes) to $S \& T R$, Mail Stop L-664, Lawrence Livermore National Laboratory, P.O. Box 808, Livermore, California 94551, or telephone (925) 422-8961. Our electronic mail address is str-mail@llnl.gov.

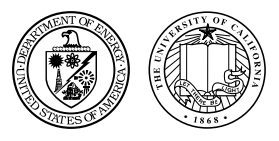

Prepared by LLNL under contract No. W-7405-Eng-48 (c) 1998. The Regents of the University of California. All rights reserved. This document has been authored by the Regents of the University of California under Contract No. W-7405-Eng-48 with the U.S. Government. To request permission to use any material contained in this document, please submit your request in writing to the Technical Information Department, Publication Services Group, Lawrence Livermore National Laboratory, P.O. Box 808, Livermore, California 94551, or to our electronic mail address report-orders@llnl.gov.

This document was prepared as an account of work sponsored by an agency of the United States Government. Neither the United States Government nor the University of California nor any of their employees makes any warranty, expressed or implied, or assumes any legal liability or responsibility for the accuracy, completeness, or usefulness of any information, apparatus, product, or process disclosed, or represents that its use would not infringe privately owned rights. Reference herein to any specific commercial product, process, or service by trade name, trademark, manufacturer, or otherwise, does not necessarily constitute or imply its endorsement, recommendation, or favoring by the United States Government or the University of California. The views and opinions of authors expressed herein do not necessarily state or reflect those of the United States Government or the University of California and shall not be used for advertising or product endorsement purposes. 


\section{S\&TR Staff}

SCIENTIFIC EdITORS

J. Smart and David Eimerl

MANAGING EDITOR

Sam Hunter

Publication Editor

Sue Stull

\section{WrITERS}

Arnie Heller, Ann Parker, Katie Walter, Dean Wheatcraft, and Gloria Wilt

Art Director and Designer

George Kitrinos

\section{INTERNET DESIGNER}

Kitty Tinsley

COMPOSITOR

Louisa Cardoza

\section{Proofreaders}

Carolin Middleton and Al Miguel

$S \& T R$ is a Director's Office publication, produced by the Technical Information Department, under the direction of the Office of Policy, Planning, and Special Studies.

Printed in the United States of America

\section{Available from}

National Technical Information Service U.S. Department of Commerce

5285 Port Royal Road

Springfield, Virginia 22161

UCRL-52000-98-10

Distribution Category UC-700

October 1998

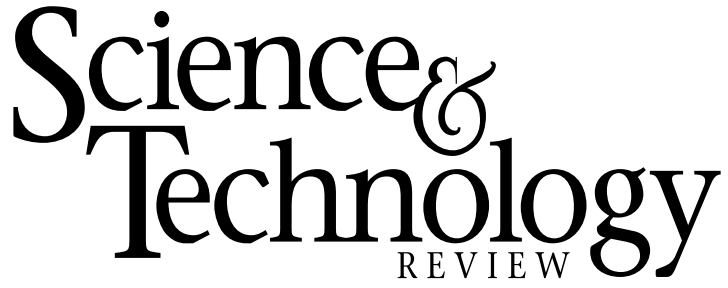

Lawrence

Livermore

National

Laboratory

\section{The Laboratory in the News}

3 Commentary by J effrey Wads worth

The Best of the Best Technologies

1998 R \&D 100 Awards

4 Putting Thieves on Notice

6 Automating Fine Grinding of Precision Lenses

8 Bridge Diagnosis at 55 mph

10 A Better Look at Dental Tissue

12 Blasts of Light to Strengthen Metals

14 Zeroing In on Low Temperatures for Surgery

16 INDUCT95 Helps U.S. Stay \#1 in Semiconductors

\section{Patents and Awards}

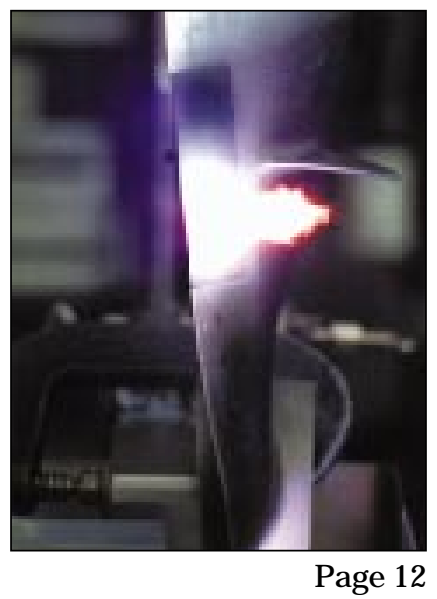

Page 10

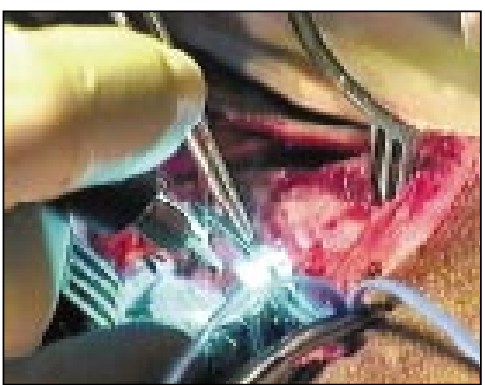

Page 14 


\section{Richardson confirmed as DOE Secretary}

On July 31, 1998, Bill Richardson was confirmed by the U.S. Senate as the new Secretary of the Department of Energy. Richardson, a former representative to Congress from New Mexico, leaves his post as the U.S. Ambassador to the United Nations to succeed former Energy Secretary Federico Peña, who resigned in June.

"I am very grateful that the Senate has moved forward expeditiously and unanimously to confirm my nomination," Richardson said. "I look forward to taking on the significant responsibilities and challenges of leading the departmentprotecting our national security, advancing the frontiers of science and technology, helping to solve the challenge of global climate change, cleaning up waste sites throughout the country, working to bring down the cost of electricity to the American people, and ensuring a balanced energy portfolio for our nation."

President Clinton said that he was "confident that Ambassador Richardson's tremendous energy, creativity, and leadership will help secure our nation's energy future so that America continues to prosper."

Laboratory Director Bruce Tarter said, "I was very glad to learn of Ambassador Richardson's confirmation by the Senate.... [H]e understands national laboratories and particularly DOE defense labs. He has been a leading figure in America's efforts to bring stability to some of the world's most dangerous regions. He has indicated his support for science, technology, and environmental responsibility-in short, the broad range of efforts that this Laboratory is engaged in. We look forward to working with him."

\section{Livermore x-ray microscope aids dental research}

Physicist John Kinney is using an $\mathrm{x}$-ray microscope developed at Lawrence Livermore to help dental researchers at the University of California at San Francisco better understand the composition and structure of teeth, particularly the porous, bonelike material called dentin. Kinney and his collaborators are using the x-ray microscope to produce high-resolution, three-dimensional images of dentin at the cell level. Their goal is to create a scientifically detailed model that leads to significant advances in dental health-in particular, better methods and materials for creating more permanent bonds between the tooth and the plastic-based fillings now being used to repair most cavities.

Contact: J ohn Kinney (925) 422-6669 (kinney3@IInl.gov).

\section{National Laser Technology Alliance formed}

Livermore's Laser Programs Associate Director Michael Campbell and L. Raymond Hettche, director of the Applied Research Laboratory (ARL) at Pennsylvania State University, recently signed an agreement forming a National Laser Technology Alliance. Like Lawrence Livermore, ARL is recognized as an international leader in laser technology and applications. The alliance marries ARL's expertise in laser processing of materials, developed through over 50 years' experience conducting defense work, with Livermore's expertise developing new laser systems.

Among the projects the alliance is considering are programs to develop new lasers for medical applications in cooperation with Penn State's College of Medicine. The alliance is also considering projects using high-powered lasers for high-speed metal drilling in the construction of military equipment and for cutting up obsolete weapons without the risk of explosion.

Contact: Richard Solarz (925) 422-6218 (solarz1@|lnl.gov).

\section{Lab reports on downside of gas additive}

In mid-June, Laboratory scientists filed a report of their comprehensive assessment of the extent to which the gasoline additive MTBE (methyl tertiary-butyl ether) has contaminated groundwater in California. MTBE is a chemical widely added to California gasoline since 1992 to reduce toxic emissions from gasoline-burning engines. Commissioned by the California State Water Resources Control Board, the Department of Energy, and the Western States Petroleum Association, the Livermore report concludes that MTBE has contaminated groundwater at more than 10,000 sites, spreads quickly through the water supply, and "may prove a cumulative contamination hazard" as it builds up in groundwater. At low concentrations, MTBE gives water a turpentinelike odor and a bitter taste. Its primary source in groundwater is leakage from underground storage tanks; in surface water, a major source is two-stroke watercraft engines that spill up to a quarter of their fuel. The Environmental Protection Agency has identified MTBE as a "possible human carcinogen." Livermore scientists found MTBE in nearly 80 percent of the 1,858 monitoring wells examined throughout the state. Groundwater provides 40 to 60 percent of the state's water supply.

Contact: Anne Happel (925) 422-9203 (happel1@IInl.gov). 


\section{궁. The Best of the Best Technologies}

A mobile radar system for inspecting bridges. Laser pulses to strengthen metal. A new kind of key that uses lasers. An imaging system that reveals the insides of teeth. A novel method to measure temperature. Computer software that boosts semiconductor production. And a detector to aid optics manufacturing efficiency.

These inventions by Lawrence Livermore researchers and their industrial partners were recently honored by $R \& D$ Magazine as seven of the top 100 technological achievements of the past year. Every year, the magazine honors the breakthrough products and processes that promise to improve people's lives. Livermore's awards for 1998 impact the construction, metalworking, semiconductor, security, medical, and optics industries. In-depth descriptions of Livermore's winning technologies begin on p. 4 .

Our seven awards for 1998 match Pacific Northwest National Laboratory's for the top spot among research institutions. This year's total also matches our previous best set in 1987, 1988, and 1997 and brings to 75 the number of R\&D 100 Awards won by Livermore researchers since 1978 . Of course, this award is only one marker of technological achievement, but given the tough competition involving the world's top corporations, government labs, private research institutes, and universities, this Laboratory has shown it can compete with the best of the best.

In total, DOE laboratories won 30 of this year's 100 awards and shared in two additional winning entries. Clearly, the DOE labs are performing some of the best applied science research in the world and yielding products that offer significant potential for commercialization.

Once again, researchers from Livermore's Laser Programs led the way, winning or sharing in five of our awards. Laser Programs has now been involved in 39 of the Laboratory's awards. However, the awards are also indicative of strong teaming across directorates, especially in the healthcare technologies.

This year, I am particularly proud of the list of outside agencies and companies that are award co-recipients and contributors. These organizations include the Federal Highway Administration, Metal Improvement Co. Inc., University of Connecticut Health Center, OptiPro Systems Inc., Center for Optics Manufacturing, and American Precision Optics Manufacturers Association.

Finally, I want to recognize Livermore's Industrial Partnerships and Commercialization Office, which coordinated the Laboratory's entries for this year's competition. The men and women in this office help American businesses access Livermore technological breakthroughs for new commercial products and services.

The award-winning technologies and their creators are: - High-Performance Electromagnetic Roadway Mapping and Evaluation System (HERMES), a high-resolution, radar-based mobile inspection system for detecting and mapping defects in bridge decks. Laser Programs and Engineering directorates with the Federal Highway Administration.

- Lasershot ${ }^{\mathrm{SM}}$ Peening System, a peening process using lasers to instill deep compressive stress in materials and thereby extend the lifetime of components such as jet-engine fan blades. Laser Programs and Engineering directorates with Metal Improvement Co. Inc.

- Light Lock Optical Security System, a laser-mediated electronic-mechanical lock with a reprogrammable code to activate the locking device. Defense and Nuclear Technologies Directorate.

- Optical Dental Imaging System, a noninvasive imaging technology to view internal tooth and soft tissue microstructure for dental applications. Livermore's Medical Technology Program with the University of Connecticut Health Center. - Two-Color Fiber-Optic Infrared Sensor, for measuring temperature and emissivity for medical and industrial applications. Medical Technology Program.

- INDUCT95, a computer software simulation tool developed for optimizing plasma-assisted manufacturing for semiconductor production. Physics and Space Technology and Defense and Nuclear Technologies directorates, with technology that grew out of a cooperative pact between the Laboratory, IBM, and AT\&T.

- The OptiPro-AED Proximity Sensor, a product substantially improving the efficiency of precision optics manufacturing by sensing the separation between fine abrasive grinding tools and optical glass parts. A collaboration of the Energy Programs, Engineering, and Laser Programs directorates and OptiPro Systems Inc. of New York.

Congratulations to all the award recipients. The R\&D 100 Awards receive considerable recognition nationwide; our success at Livermore reflects the world-class research conducted here and the collaborative efforts of our programs.

Jeffrey Wadsworth is Deputy Director for Science and Technology. 
AR thieves: beware. Jimmying a lock or punching out an

ignition switch to start and steal a car may soon be fruitless activities. If a new, Livermore-developed locking system were installed in the next car you tried to steal, you would find your theft next to impossible. After jimmying the lock, you would be faced with a fiber-optic cable activated only by a specially coded beam of light. Even if you punched out the ignition switch, an identical cable would prevent the engine from starting. Forget hot-wiring; the fiber-optic system would protect not only the door lock but also the ignition system, fuel pump, and starter.

Lawrence Livermore's Bob Clough, Karla Hagans, Richard Main, and Bob Stoddard from Defense and Nuclear Technologies and Engineering directorates developed this novel system (Figure 1). The researchers designed the optoelectronic-mechanical lock and key to secure military systems from theft and unauthorized operation, but soon the Light Lock Optical Security System could be used anywhere conventional mechanical locks are used.

\section{A Laser Beam Does the J ob}

The key is entirely different from those used today. Instead of depending on the mechanical motion of turning in the lock, this key emits laser light from a light-emitting diode or a laser diode. The lock converts the light from the key into electrical power to operate its electronics. The key's light has been "multiplexed" with the code and wavelength required by that particular lock, so the lock must compare the transmitted code from the light to the code it has stored in memory. If they match, the lock opens (Figure 2).

Unlike standard mechanical locks, which have a mechanical connection between the key and the bolt mechanism, Light Lock has no connection, making it almost impossible to manipulate the locking mechanism. In conventional locks, the primary area of weakness is that mechanical connection. A common method of attacking these locks is to bore out the key access and turn the dead bolt. But with no mechanical connection between the key and the bolt, that strategy will not work.

The lock is totally passive with no internal power supply, and the only connection between the key and the lock is light. The combination for the lock can be made to any length desired and can include information other than the code, such as the user or the intended use. The power required by the

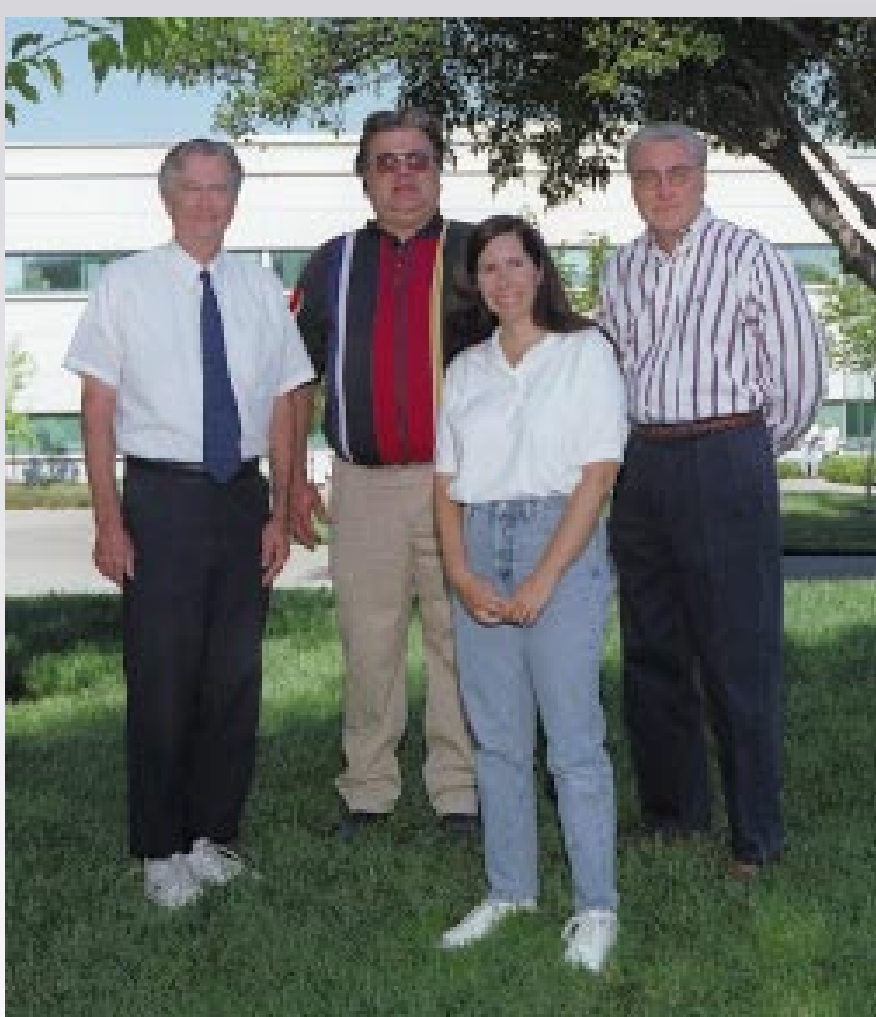

Figure 1. Light Lock O ptical Security System research team includes (left to right) Robert Clough, Richard Main, Karla Hagans, and Robert Stoddard.

Light Lock Optical Security System is similar to that found in a typical laser pointer. An added plus is that the key and lock are easily reprogrammed.

Another advantage of this system is that the key and the lock can work together even if they are separated from one another. The laser light from the key can travel along a fiberoptic cable to a vault, for example, that is secured in a buried enclosure. This remote operation feature makes it effective for securely granting access to sites that are a long distance from the person authorizing access.

\section{Computer Data Locked Up Tight}

Light Lock can be used not only in place of mechanical locks but also like a password for data access control. A slot in 
a computer keyboard could accept a Light Lock key or card to activate a lock imbedded in the system. If the key were removed, the terminal would automatically lock up. A key could be "tethered" to an operator so that the operator could not leave a terminal without removing the key. This setup would eliminate unauthorized access to an unattended terminal.

Because Light Lock can transmit information about the authorized key user, an audit trail could be established using the access code and the operator code. Using the computer system's time and date information, each transaction, modification, or access could be stamped and saved. Operator codes in the Light Lock key could also determine levels of access to an application or to a collection of files.

\section{No Competition}

No product on the market today competes directly with the Light Lock. It has just one moving part, compared with about 30 on a combination safe and 20 in a conventional tumbler lock. It offers almost 17 million possible combinations, about $40 \%$ more than a combination safe and 10 times more than a tumbler lock. Unlike recently designed electromechanical locks, which are not as effective as conventional mechanical locks, Light Lock uses optics in a novel way to create a unique, highly effective security mechanism for protecting valuable assets.

Two things stand in the way of wide acceptance of Light Lock: its size and cost. Within about a year, the team expects to have both problems solved, with a key that is considerably smaller than the current 6 -inch length and production costs decreased from about $\$ 200$ per lock to about $\$ 50$.

Once those changes are made and Light Lock systems begin to appear on safes, vehicles, homes, industrial facilities, and computer databases, thieves may discover that they are completely out of luck. Even if they know about optoelectronics, they won't be able to overcome the combination of light, electronics, and software.

-Katie Walter

Key Words: fiber-optic systems, laser systems, Light Lock Optical Security System, optoelectronic-mechanical locks, security systems.

For further information contact Robert Stoddard (925) 422-4877 (stoddard1@IInl.gov).

(a)
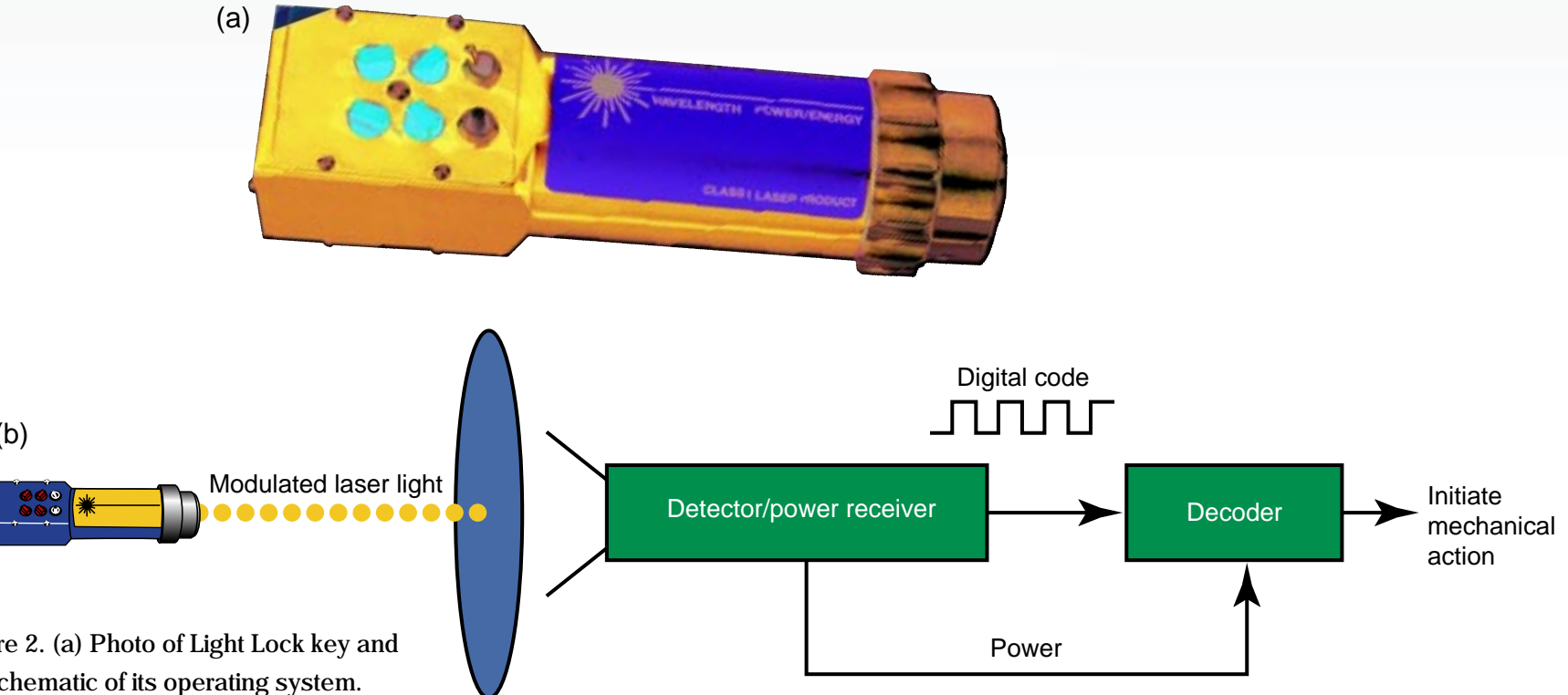

(b) schematic of its operating system. 


\section{R\&D 100 Awards}

\section{Automating Fine Gr inding of Precision Lenses}

$\mathrm{N}$ the cost-conscious world of manufacturing, any new process that saves time and money is likely to be very popular. This is especially true for precision optical components, which would be more widely used if they cost less to produce. Livermore's award-winning OptiPro-AED (acoustic emissions detector) should help make the grinding process a reality.

The vast majority of optics produced in this country-for disposable cameras, binoculars, and gunsights-are relatively inexpensive to manufacture. But the highest quality systemsfound in military night vision systems, medical endoscopes, and machine vision systems for aligning parts, for examplerequire higher quality lenses, which need additional grinding and polishing. Fine grinding, typically the last step before polishing, is now a relatively labor-intensive task that drives up the cost of precision optics.

Fine grinding is a sensitive operation. The relatively fast speed of the grinding tool must be slowed down as it approaches the lens for fine grinding. If the grinding tool strikes the optic at too high a speed, the optic's surface will be damaged. The speeds and motions of the grinding operation are computer-controlled, but directing the fine-grinding tool toward the optical surface-a process known as in-feedingrequires human intervention for as long as several minutes. An operator gingerly feeding the fine-grinding tool toward the lens may not be sure if and when contact is actually made. Fluid to cool the grinding operation flows at several liters per minute, creating a torrent of fluid between the rotating tool and workpiece that makes visual proximity measurements impossible. Efficient and safe computer control of the process has not been possible in such an environment.

\section{A Gentle Touch Does It}

Livermore engineers Mark Piscotty, John S. Taylor, and Kenneth Blaedel (Figure 1), working with Mike Bechtold of OptiPro Systems Inc. of Ontario, New York, have developed a device known as the OptiPro-AED Proximity Sensor, which automatically detects the separation between the grinding tool and the lens (Figure 2) using an acoustic-emission detector (AED). With this device, the in-feeding operation may join the ranks of fully computer-controlled processes used to

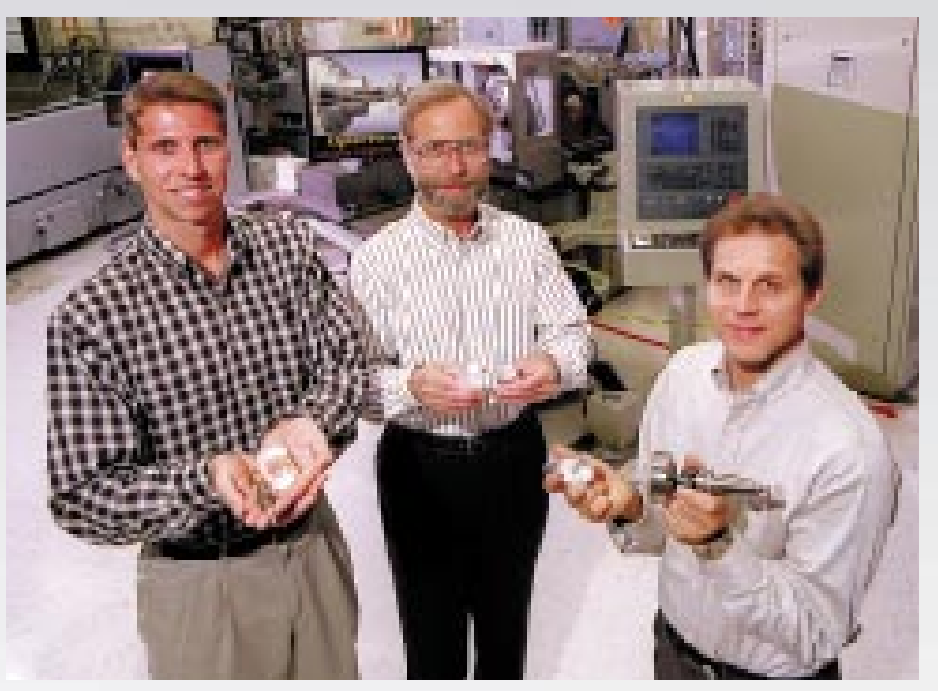

Figure 1. The Livermore research team of Mark P iscotty, J ohn S. Taylor, and Kenneth Blaedel (left to right) holds sample optics and the proximity sensor of the OptiP ro-AED.

manufacture optical components. The grinding tool can automatically and efficiently approach the lens without risk of crashing into the fragile lens surface and with minimal loss of production time.

Funded under a cooperative research pact and by Lawrence Livermore's Small Business Program, this advance grew out of a project between the Laboratory, the Center for Optics Manufacturing, and the American Precision Optics Manufacturers Association, of which OptiPro Systems is a member.

Notes Piscotty, "The acoustic-emission levels generated in fine grinding prior to contact are at least ten times less than background levels produced by typical grinding machines. This device must therefore be extremely sensitive to be able to sense these smaller signals in a very noisy environment."

The OptiPro-AED is a piezoelectric acoustic-emission sensor mounted in a probe assembly that is inserted in the spindle of the optic being ground. The sensor is coupled to the optic through a lightly spring-loaded contact probe, which gently touches the 


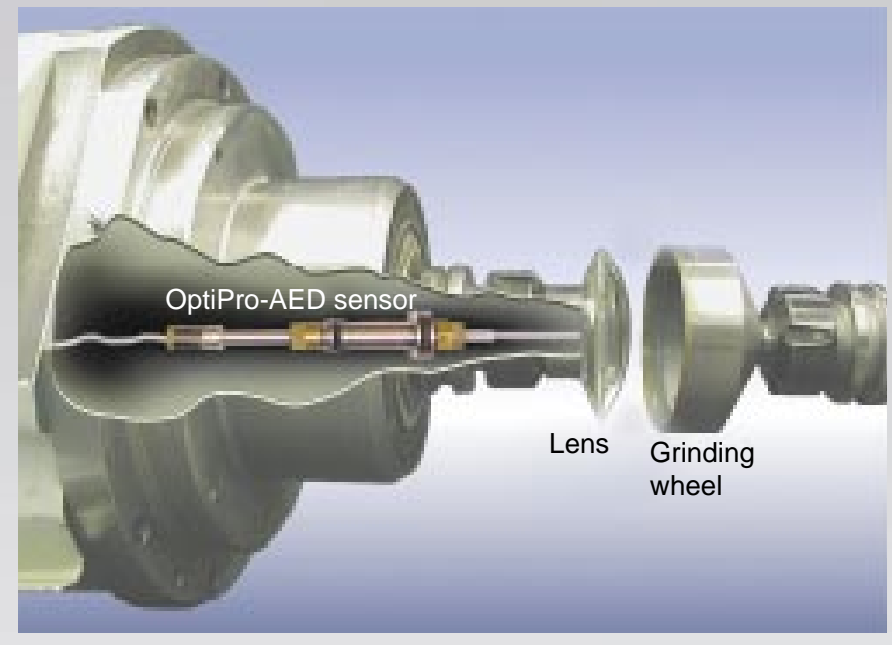

Figure 2. The OptiPro-AED automates the in-feeding rate of a finegrinding tool. Its acoustic-emission pickup sensor inside the workpiece spindle transmits the signal to a signal processor and computer controller.

backside of the optic. The entire assembly is acoustically isolated from the spindle and the machine. This unique design enables the small acoustic-emission signals to be detected in the presence of swirling coolant and background machine noise.

The sensor incorporates commercially available acousticemission equipment to detect signals generated by the relative motions of the rotating grinding tool, rotating glass optic, and coolant fluid. The turbulence created in the coolant generates signals that are strongly dependent on the gap between the moving tool and the workpiece.

OptiPro Systems Inc. has already begun integrating the OptiPro-AED into a commercial line of lens-grinding equipment. Recent tests show that the OptiPro-AED infeeding process is more than ten times faster than traditional manual methods.

Some manufacturers of optical components have omitted the fine-grinding step because it is so labor intensive. But without fine grinding, the final polishing operation takes longer. The OptiPro-AED is expected to entice optics manufacturers to incorporate fine grinding into their production lines, improving productivity and lowering the cost of precision optics.

\section{There's No Comparison}

Other commercially available sensors, which detect when a grinding tool touches the piece being manufactured, are appropriate for use during coarse metal machining and grinding. If only a contact sensor is used during fine grinding of optical

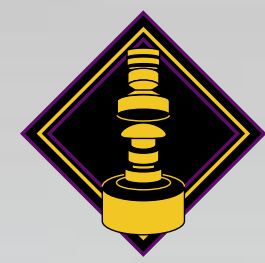
components, the workpiece and possibly the grinding tool can be damaged upon contact.

The OptiPro-AED measures the proximity of the tool to the workpiece, making it the only sensor useful for fine grinding of optical components. The proximity measurements tell the computer controls when to decelerate the tool prior to contact with the optic so that no damage occurs. This sensor is also the only one designed to work specifically under the optics industry's wet grinding conditions.

\section{Expanding Use}

The OptiPro-AED may also have applications in the semiconductor industry, which requires high surface quality and little or no subsurface damage in silicon wafers. The OptiPro-AED could greatly improve the economics of grinding wafers, enabling grinding to complement or even replace industry-standard chemomechanical finishing methods.

During a grinding operation, the acoustic emission signals may also be put to a completely different use-to determine when a grinding tool is worn and requires reconditioning (dressing) to avoid producing lower-quality parts. This use of the acoustic-emission instrumentation could significantly reduce the number of inspections needed to ensure proper tooling performance.

If the precision optics industry adopts the OptiPro-AED, several spinoffs will ensue. The cost to produce some optical components already being manufactured should drop. More importantly, fully automating the fine-grinding process will improve the economics of producing precision optics in large volumes. If precision optics are less expensive, they will have much wider use than they do today-in defense, medical, and manufacturing applications as well as in a broad array of consumer goods.

- Katie Walter

Key Words: acoustic-emission detector, grinding, optics manufacturing, OptiPro-AED, proximity sensor, precision engineering. 


\section{Bridge Diagnosis at $55 \mathrm{mph}$}

S AY the words "closed" or "construction ahead," and see despair cloud a driver's face. It's hard enough to drive on roadways these days without added disruptions. But happen they will because some \$20-billion worth of highway infrastructure maintenance must be done each year in the U.S. to keep motorists on the move safely. State departments of transportation-owners of most of the nation's highways-face this large workload with scarce maintenance resources; they could use new technologies to help perform tasks faster, cheaper, and more effectively.

The Federal Highway Administration (FHWA) has helped sponsor a research project at Lawrence Livermore that produced a beneficial new tool as well as an R\&D 100 Award. The HERMES Bridge Inspector will provide an invaluable capability to diagnose the problems of deteriorating bridge decks and do it accurately, efficiently, nondestructively, and, perhaps most important to motorists, without closing bridges. Almost $30 \%$ of 600,000 large highway bridges in the U.S. are classified "deficient" by the FHWA, and HERMES can make a significant contribution toward solving the problem of infrastructure assessment and repair. With further development, HERMES holds promise for other concrete inspection problems, such as railroads, tunnels, and runways.

HERMES, or High-performance Electromagnetic Roadway Mapping and Evaluation System, is a radar-based sensing system mounted in a trailer. It can be pulled by a vehicle at traffic speeds over a bridge deck to collect information about the roadway subsurface-its sensors gathering data 30 centimeters or more into concrete. An onboard computer system processes the data into three-dimensional images that pinpoint problems in the roadway concrete and give engineers quantitative information about deterioration in the bridge deck. Engineers can then better assess what repairs or reconstruction is necessary and avoid the cost overruns and delays that result from inexact problem diagnoses.

HERMES technology is a radical change from conventional bridge inspection methods in use today. Most inspections are still done visually - with inspectors looking for external manifestations of internal flaws-a tedious and not completely reliable method. Another conventional inspection method uses sound: after the top layer of asphalt is stripped off, an inspector with a trained ear "listens" for faulty concrete as chains are dragged over the underlying concrete. The latter technique is costly, requiring time-consuming bridge closure, asphalt removal, and resurfacing.

In contrast, when put to the test last summer in Weaverville, California, HERMES quickly and accurately found significant problems on the Grass Valley Creek Bridge, where retrofit work

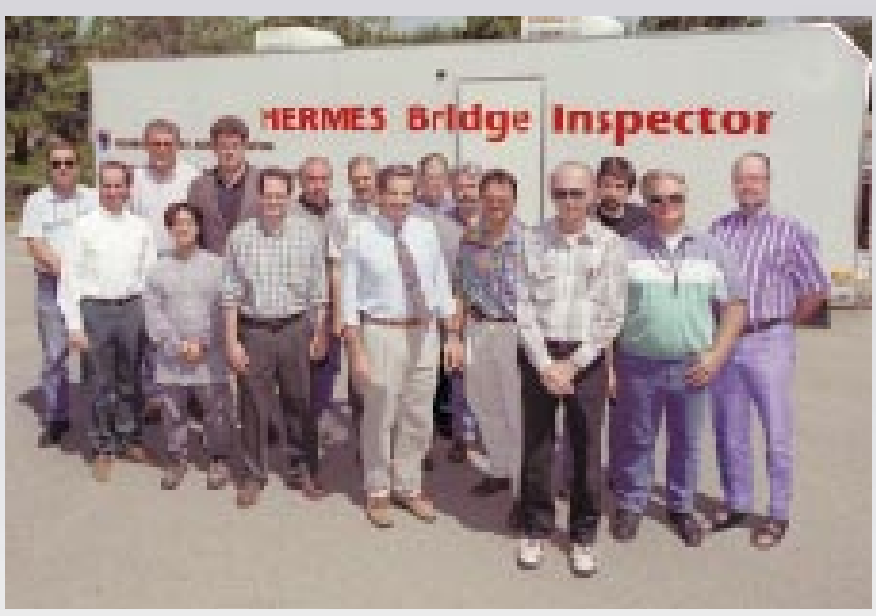

Figure 1. Trailer containing the HERMES Bridge Inspector system. Livermore team members include (left to right front row) Scott Nelson, Ming Liu, J eff Mast, Stephen Azevedo, J ose E. Hernandez, Bob Stever, and Richard Gilliam; (back row) Tom Story, Mark Vigars, Tom Rosenbury, Greg Dallum, Holger J ones, Pat Welsh, George Governo, and J ohn Warhus.

had been scheduled. The internal flaws revealed the need for a complete deck replacement instead of the planned rehabilitation. What HERMES "saw" was verified once work began and the roadway's top asphalt layer was removed. Consequently, the bridge repair project had to be revised, causing a delay of a year and a million dollars in costs that could have been avoided had HERMES been available before the bidding process began.

\section{Applying MIR Technology Again}

The idea for using radar to inspect bridges was born out of the Laboratory's expertise in pulsed power and computational imaging and a collaboration with the FHWA. Engineering's Karl Freytag and the FHWA's Structures Division Manager Steve Chase foresaw the need for a visualization tool for infrastructure assessments. Under Engineering's initial funding and the FHWA's sponsorship and guidance, HERMES researchers experimented with a number of approaches to system development and settled on a small impulse radar sensor developed at Livermore as the visualization technology.

Micropower impulse radar (MIR) is a spinoff invention from Livermore's laser fusion diagnostics work in transient digitizers, itself an R\&D 100 winner in 1993 (see articles in E\&TR, April 1994, and S\&TR, January/February 1996). Since the first award, 


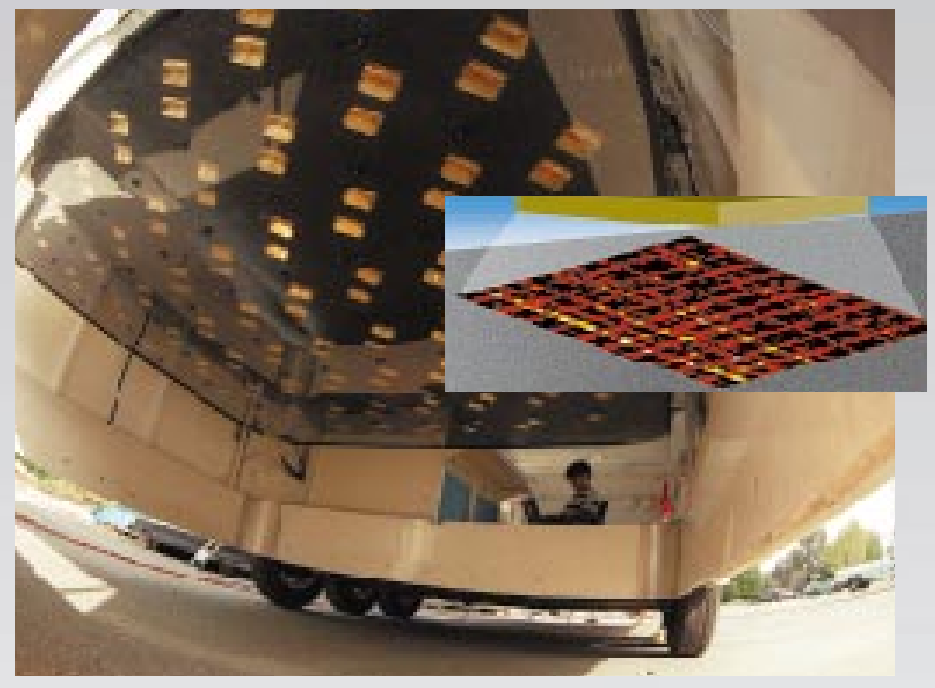

Figure 2. A fisheye-lens view of HERMES modules from under the rear door. The array of 64 radar modules can be raised and lowered in the bottom of the trailer. Inset image shows the condition of rebar in a bridge deck.

MIR has been applied to numerous uses, ranging from an electronic dipstick to measure fluid levels in automobiles (winning another R\&D 100 Award in 1996; see $S \& T R$, October 1996) to a land-mine detection system (S\&TR, November 1997). Much of the MIR development and the current MIR projects have been headed by Stephen Azevedo.

Experiments using MIR to image concrete slabs showed vast improvements over the higher-powered, lower-frequency systems tested earlier. At the same time, Laboratory engineers were developing unique three-dimensional reconstructive imaging software, using diffraction tomography that was refined to "see" through layers of material.

In contrast to conventional radar, which uses continuous microwave energy to detect objects over many miles, impulse radar transmits ultrashort electromagnetic pulses that allow the detection of objects at very short ranges. MIR's pulses, producing a wide band of frequencies, generate a great deal of information about detected objects at high resolution and accuracy. The echoes of these pulses are measured by an extremely sensitive receiver that is set for a detection range of a few centimeters to many tens of meters. MIR system components also include timing circuitry, a signal processor, and antennas. Together, they determine system range, directionality, and how well materials such as water, ice, and mud can be penetrated.

An MIR system is compact and lightweight and has low power requirements; it is cheaper to produce than a conventional radar system and is amenable to many more applications. Furthermore, MIR modules can be grouped into arrays to increase system speed and area of coverage.
For HERMES, 64 high-speed impulse radar modules were mounted underneath the HERMES trailer to send out very fast, short pulses -1 to 5 gigahertz-into the ground, penetrating roadway concrete to a depth of up to 30 centimeters. As the pulses propagate through the bridge deck, concrete defects alter the return signals because of the change in dielectric constant. These alterations are recorded by the computer system located inside the trailer. As the array of radars is driven over the bridge, a three-dimensional map of the deck is constructed using sophisticated imaging software. The map shows in remarkable detail the reinforcement bars, delaminations, faulty concrete, and other anomalies that occur in the inspection area.

One engineering challenge was to configure all 64 radar modules to fit underneath a normal-width trailer yet be sufficiently separated to avoid causing interference. The HERMES team, now headed by Jose E. Hernandez, experimented with several arrangements before settling on the final configuration of eight rows of eight MIR modules. Insulating foam between modules minimizes crosstalk.

\section{Down the Road}

The project team continues to gain understanding of the images the system generates and of how to better design the next generation of bridge inspectors for improved detection capability, higher speed, ruggedness, and eventual transfer to the private sector. On the road again in July 1998, HERMES could be seen testing its system upgrades on bridges along highway I-80 near Truckee, California. Also, the HERMES team is using electromagnetic models for analyzing the radar data to understand how concrete inhomogeneities, temperature differences, chemical processes, and normal concrete structures contribute to the imaging results. This modeling will enable them to predict inspection results under varying conditions and suggest changes to the radar parameters and detection algorithms.

The HERMES Bridge Inspector will save the public moneyup to $\$ 100$ million per year, according to FHWA estimates - and inconvenience. Even more important, it will result in higher confidence and safety in our public roadways.

\section{-Gloria Wilt}

Key Words: HERMES Bridge Inspector, infrastructure maintenance, micropower impulse radar (MIR), nondestructive evaluation, roadway inspection, ultrawideband sensors.

For further information contact J ose E. Hernandez (925) 423-2160 (jeh@IInl.gov). 


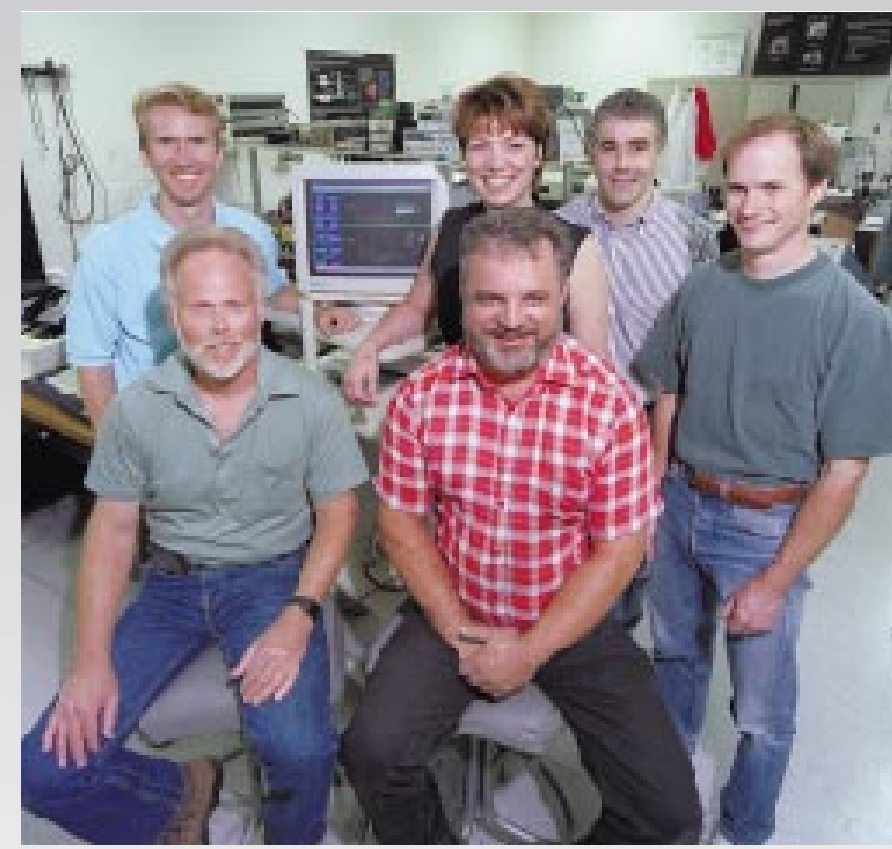

Figure 2. $R \& D 100$ Award-winning team that developed the Optical Dental Imaging System includes (left to right, front row) J im Cox, Ken Haney, (back row) Bill Colston, Linda Otis (from the University of Connecticut), Luiz Da Silva, and Matt Everett.

\section{Scanning with Finer Detail}

The dental imaging system includes a scanner (Figure 1a), interferometer, and demodulation electronics. To detect an image, a handheld scanner focuses light from a low-coherence diode light source on the tissue being examined. Different points through the axis (depth) of the tissue can be scanned by moving the reference arm of the interferometer. When the arm is moved in parallel motions across the sample, transverse scans are produced that can be combined with axial information to create two-dimensional plots or images of cross sections.

An image can show, for example, features relevant for diagnosing periodontal diseases (Figure $1 \mathrm{~b}$ and $\mathrm{c}$ ), the plaqueinduced disorders that result in deterioration of connective tissue and resorption of alveolar bone. The imaging system provides in vivo images that allow a dentist to determine with great accuracy the state of the tissue and how well it is attached. Imaging the hard tissue structure can also provide a safe and noninvasive alternative for locating sites of potential and actual cavities, making possible the early treatment that will prevent or stop their progress.

Inadequate seals between restorations and the gingival margin can result in infection, dissemination of bacteria, and loss of supporting tooth structure. OCT images, for example, can also show such structural restoration defects before significant leakage occurs. Because techniques currently used for evaluating

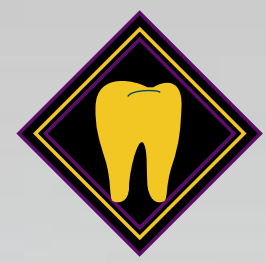
restorations are inadequate, the OCT technique can help minimize tooth loss and decrease unnecessary replacement of restorations.

Colston and the other team members (Figure 2) are engineering the system to make it small enough for dentists to handle, easily usable without additional training, and inexpensive to produce.

-Gloria Wilt

Key Words: dental diagnostics, Optical Dental Imaging System, optical imaging. 

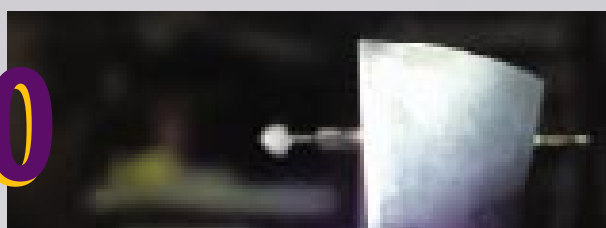

Str engthen

A T first glance, it would seem that bombarding a metal part with an intense stream of tiny metal or ceramic balls might not be the best approach for making that part more resistant to cracking and corrosion. And yet, shot peening is a tried-and-true technique for strengthening metals. Now a team of Lawrence Livermore researchers, in tandem with colleagues at New Jersey-based Metal Improvement Co. Inc., have replaced the tiny balls with short-lived, repetitive blasts of light from a reliable, high-powered laser.

The new technology, called the Lasershot ${ }^{\mathrm{SM}}$ Peening System, is designed to extend the service lifetime of critical metal parts, from aircraft engine fan blades (Figure 1) to hip joints, by a factor of three to five times over conventional peening treatments. The process also holds the promise of lighter, stronger products of entirely new designs.

In traditional shot-peening procedures, each metal or ceramic ball acts as a minuscule ball-peen hammer, imparting on a metal surface a small indentation or dimple. This process produces, below the dimple, a hemisphere of highly shocked and compressed material. In time, overlapping dimples provide a very thin (about 0.25 millimeter), uniform layer that is extremely resistant to cracks, corrosion, and fatigue. Because of these benefits, the springs and transmission components of almost every automobile are shot peened for longer life, as are aircraft structural components.

With the invention of the laser, researchers quickly recognized that peening could be achieved using high-energy lasers with pulse lengths in the tens of nanoseconds (billionths of a second), short enough to generate a rapid yet energetic shock. Prototype laser peening machines were developed in the 1970s, but they and subsequent versions over the past two decades were not cost effective because the lasers lacked the high repetition rate required for treating parts rapidly.

\section{Borrowed Technology}

Working under a Department of Energy Cooperative Research and Development Agreement, the team of researchers from Livermore (Figure 2) and Metal Improvement Co. developed a machine that for the first time makes laser peening a cost-effective option by providing a tenfold increase in metal part treatment rate over all other laser systems. The Lasershot ${ }^{\mathrm{SM}}$

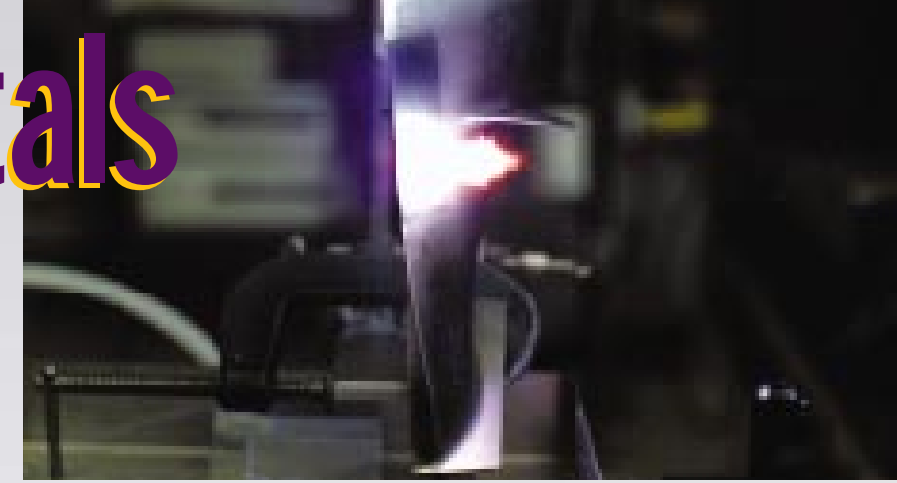

Figure 1. A jet-engine fan blade being treated by the Lasershot Peening System. This system induces deep compressive stress to significantly extend the service lifetime of high-value parts three to five times longer than conventional treatment.

Peening System features a 600-watt, high-energy (100-joule), neodymium-doped glass laser capable of firing 6 pulses per second continuously and 10 pulses per second in bursts.

In use, the system fires a 20-nanosecond laser pulse that is focused to an energy density of about 200 joules per square centimeter at the surface of a metal coated with dark paint and a thin overlay of transparent material, like water. The laser light passes through the water and is absorbed by the dark paint. The interaction creates a pressure shock wave in the range of 10,000 atmospheres $(150,000$ pounds per square inch) that in turn creates a deep compressive stress layer directly underneath the focused pulse. (The water layer acts like a lid on a pot to help contain the shock.)

The system borrows from major advances made in the past decade by Livermore's laser fusion program. Like Livermore's giant Nova laser, Lasershot employs neodymium-doped glass, a master oscillator for originating and then amplifying the laser pulse, a much stronger amplifier optically pumped by flashlamps, and more recently, an active laser wavefront correction that allows the highenergy laser to be operated at high repetition rates. Indeed, says Livermore physicist Lloyd Hackel, a laser system based on neodymium-doped glass is the only identified technology that can realistically achieve the required energy output with acceptable pulse duration.

According to Hackel, the most significant feature of the system is the laser's high repetition rate, which enables the system to treat parts at about the same rate as conventional peening and at a substantially faster rate than existing laser peening methods. "Until now, the lack of a fast enough laser repetition rate has held back laser peening from significant adoption by industry," he says. 


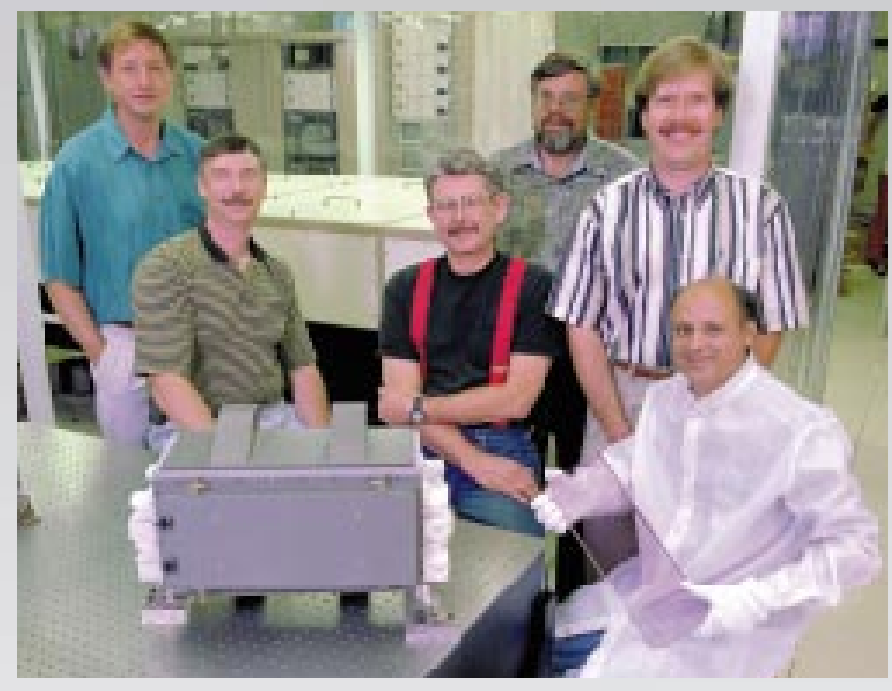

Figure 2. Livermore researchers who developed the Lasershot ${ }^{\mathrm{M}}$ Peening System include (left to right) Lloyd Hackel, Bill Manning, J im Wintemute, Steve Telford, Brent Dane, and Balbir Bhachu.

The new system does not have the kinetic energy limitations of metal or ceramic shot. As a result, it can induce a compressive stress layer more than 1 millimeter (0.04 inch) thick, some four times deeper than that obtainable with shot. The increased depth effectively extends the service lifetime of parts some three to five times over that provided by conventional treatments, an increase essential for preventing cracking on blades, rotors, and gears. In fact, tests on deliberately nicked (and hence weakened) turbine fan blades show that laser peening will actually render these parts stronger than new, unflawed-but not laser-peened-blades.

A unique advantage of Lasershot's laser pulse is its square profile. A typical laser's round output beam requires overlapping spots on a metal surface in an inefficient manner, but the new system allows full coverage of each square spot directly adjacent to the next. What's more, the system automatically maintains the laser-pulse wavefront near the physically allowable limit, enabling higher power without worry of laser glass damage or damage to the treated part.

\section{Strength for Future Products}

The first commercial use of the technology is expected in late 1999. With Livermore support, Metal Improvement Co., the nation's leading provider of metal-peening services, has been introducing the new product to the manufacturing and user community and has received very high interest. Hackel anticipates that many companies will send parts to Metal Improvement Co. for treatment, engineering evaluation, and production. An option for large firms like aircraft and automobile parts manufacturers is purchasing and operating their own Lasershot system.

Hackel says the new process will probably not replace conventional shot

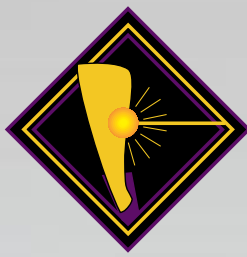
peening but instead will be used in areas where greater depths of compressive stress are desired, such as jet engine rotors, disks, blades, gears, and shafts. In these cases, component cost is high, and resistance to metal fatigue is extremely important. Recent studies showed that engine blades costing $\$ 30,000$ to $\$ 40,000$ apiece last three to five times longer when treated with the laser-peening process. Lasershot is also expected to increase the resistance of turbine blades to objects such as birds, ice, and stones that can damage the edge of a blade and trigger small cracks.

Other industrial applications include oil tools (drill collars, bits, and mud pumps), marine and rocket engine parts, golf equipment, and even hip joints. "We're going after high-value parts," says Hackel. "If we can triple the lifetime of a $\$ 30,000$ part, the cost of peening becomes insignificant." Likewise, he says, doubling the lifetime of a hip implant becomes a virtually priceless advantage for doctor and patient.

Looking to the future, Hackel notes that laser-peened parts, because of their strength, can be made thinner and thus lighter. The new-found strength in turn will free engineers to think differently about how they can design products. One potential result, says Hackel, will likely be products that need less energy to operate.

The technology underlying the laser system was originally supported by the Defense Advanced Research Projects Agency (DARPA) of the Department of Defense for a far different purpose than working metal parts. DARPA was searching for a method to convert infrared light to high-power, shortwavelength $\mathrm{x}$ rays as a light source for printing advancedgeneration integrated circuits.

More recently, funding was provided by the U.S. Navy and the U.S. Air Force. The military branches are interested in obtaining a light source for long-range and highly coherent illumination of missiles and space objects. One of the lasers has been in service since 1995 at a Navy facility at the Kennedy Space Center in Florida. A second, more powerful and longer pulse (600-nanosecond) version was recently delivered to the Air Force Research Laboratory in New Mexico.

Clearly, the future is bright for Lasershot and high-repetition, high-powered lasers.

-Arnie Heller

Key Words: high-energy laser, high-repetition-rate laser, laser peening, Lasershot ${ }^{\mathrm{SM}}$ Peening System.

For further information contact Lloyd Hackel (925) 422-9009 (hackel1@Ilnl.gov). 

the target material-without touching the surfaces involvedcan be critical. In laser tissue welding, laser energy activates tissue bonds between the surgical surfaces, fusing them together. If there's too much heat, the tissue is damaged, and poor healing results. If there's not enough heat, the bonds don't form. For semiconductors, too much heat during the dry etching process can glue or "crosslink" the thin photoresist layer to the silicon wafer.

An award-winning, Two-Color Fiber-Optic Infrared Sensor developed by Ward Small IV and others in Livermore's Medical Technology Program (Figure 1) not only measures temperatures in this critical temperature regime, but also measures the emissivity, a number between zero and one that indicates how well a target emits infrared radiation, that is, heat. (For example, highly reflective surfaces are generally poor emitters and thus have emissivities close to zero. A piece of black-painted metal, on the other hand, has an emissivity close to one.)

"This low-temperature regime -50 to $80^{\circ} \mathrm{C}$-is of particular interest in the medical field, where lasers are becoming the tool of choice for therapeutic and minimally invasive surgical procedures," says Small.

Most commercial infrared sensors measure surface temperatures of hundreds or thousands of degrees Celsius. The difficulty with measuring surfaces near room temperature is that such surfaces emit infrared signals that are weak and don't easily transmit because of their longer wavelength. The few sensors that do measure in this temperature regime assume an emissivity of 1 or a lack of sufficient spatial resolution. "Ours is the only low-temperature, noninvasive sensor with high spatial resolution that measures both temperature and emissivity," notes Small.

Measuring both variables significantly reduces the error that creeps in when measurements are taken in only one infrared wavelength band, or color. This error can be as high as $40 \%$ for materials that have a moderately reflective surface.

\section{How It Works}

The sensor is part of a temperature feedback system (Figure 2) invented by program researchers investigating surgical applications. The sensor has a single 700-micrometer-

bore, hollow-glass optical fiber mounted on one prong of a two-pronged welding handpiece. The other prong is the silica optical fiber that transmits the laser beam that welds the tissue.

While the laser beam is heating the tissue surface, the sensor's hollow fiber collects and transmits the infrared radiation from the surface to a reflective optical chopper, which modulates and splits the signal into two paths-one for each band. Two

thermoelectrically cooled mid-infrared photoconductors monitor the chopped signals, which are recovered using lock-in amplification. Using a single optical fiber for both wavelength bands guarantees that the radiation transmitted in each path originates from the same geometric region on the target.

"This means we're getting true values for the temperature and emissivity. This may not be the case in systems that have separate fibers to collect radiation for each band," explains Small.

In addition, the hollow fiber optic has a small numerical aperture, which means it collects radiation coming from one particular direction and, hence, a very small surface area. This configuration has two advantages. First, the distance between the fiber tip and the target surface can be varied without affecting the accuracy of the measurements. Second, the small 


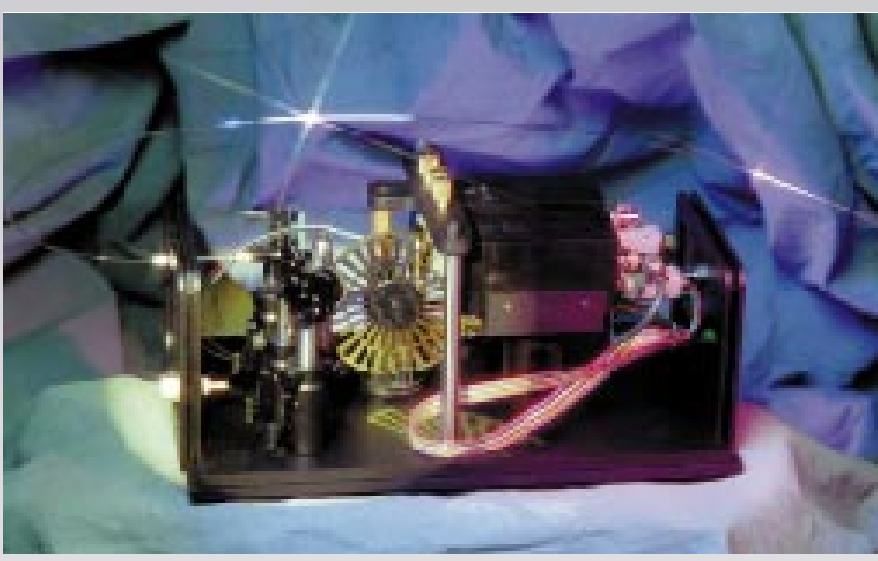

Figure 2. Livermore's temperature feedback system, including the award-winning sensor. A two-color infrared temperature sensor controls the laser used to heat the weld site.

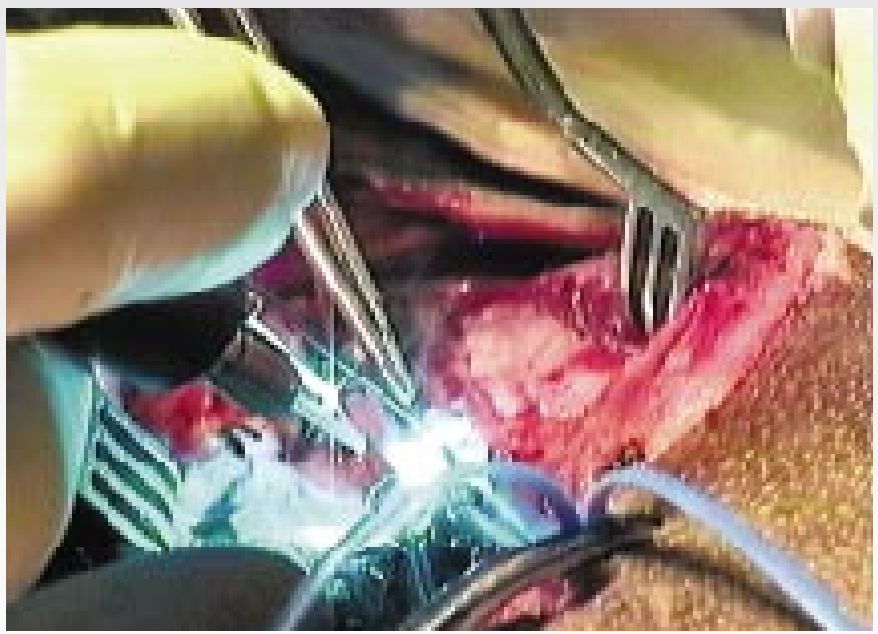

Figure 3. Photo taken during a feasibility study on an animal subject, performed at UCLA Harbor Medical Center, showing the laser delivery handpiece with the hollow fiber for sensing temperature. The surgeon is performing a 1-centimeter-long arteriotomy.

numerical aperture offers high spatial resolution. "We can accurately monitor the surface temperature of a 0.8 -millimeter spot at a distance of 1 centimeter," explains Small. "Other noninvasive sensor systems, because of their design, cannot offer the combination of submillimeter resolution and variable working distance." The variable working distance means that the surgeon can more easily maneuver around the surgical site while still obtaining accurate temperature measurements.

A computer algorithm then calculates the true temperature and emissivity of the target in real time, taking into account reflection of the laser and ambient light from the target surface. Finally, the computer uses this information to open or shut a

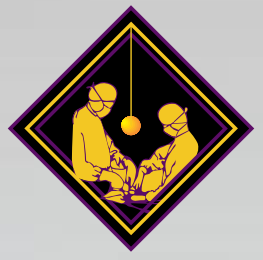

mechanical shutter, allowing more laser energy to pass if the temperature is too low or cutting off the energy if the temperature is too high.

"Because we use photoconductors that have nanosecond response times and millisecond lock-in integration times, we can accurately monitor most thermal processes," Small notes.

\section{The Acid Test}

An in vivo feasibility test of this sensor conducted at the Harbor Medical Center of the University of California at Los Angeles (UCLA) using an animal subject (Figure 3) showed that the feedback from this temperature sensor system helps to optimize and improve the consistency of the final laser weld. In the test, an expert laser surgeon performed tissue welds with the sensor and without the sensor. The finished welds were then tested for burst strength. Of the two, the weld created with the sensor feedback loop proved the stronger.

The team also performed simulations of this experiment to show that welds without the benefit of temperature control have higher, potentially more damaging, internal temperatures. This simulation shows surgeons that even though they watch the surface for clues that the temperature is too high, the tissue heats up more underneath the surface. Overheating can lead to poor healing and can kill the tissue.

\section{For the Future}

The process has a broad range of surgical applications, including vessel grafts and repair, skin wound closure, and nerve repair. For any target that has unknown or variable emissivity, the sensor provides fast, noninvasive, highresolution temperature measurements.

The Laboratory is now collaborating with Conversion Energy Enterprises as well as the University of California campuses at San Francisco and Davis to research the use of this temperature-controlled laser technique to repair congenital aorta defects in infants. Initial results show that blood leakage can be reduced by as much as $70 \%$ when this technique is used with conventional sutures.

-Ann Parker

Key Words: infrared sensor, laser surgery, optical fiber, semiconductors, Two-Color Fiber-Optic Infrared Sensor.

For further information contact Peter Celliers (925) 424-4531 (celliers1@IInl.gov). 
$\mathrm{N}$ the fast-paced semiconductor industry, staying ahead means optimizing and controlling the manufacturing processes down to the atomic level wherever possible. At stake is the \$44billion market in integrated circuits that power computers, communication devices, and consumer electronics.

INDUCT95, a unique simulation code developed by Livermore physicist Peter Vitello (Figure 1), may give the U.S. a leg up in the race. INDUCT95 helps designers of plasma-aided semiconductor manufacturing to optimize the process and equipment. Such tools are also used in the aerospace, automotive, steel, and biomedical industries.

Plasmas-gases containing ions and electrons-are widely used to fabricate microelectronic devices. Out of the nearly 800 steps to create today's intricate integrated circuits, nearly onethird use plasmas.

The increasing use of plasmas for etching, deposition, and other processes reflects the advantages of this technique. First, the plasma breaks down the gas molecules into chemicals that etch materials very rapidly. Second, the plasma ionizes chemicals, giving them an electrical charge that renders them maneuverable. Finally - and of key interest to chip manufacturers-plasma etching produces nearly perfect vertical etching profiles. Getting exact profiles of uniform depth is extremely important: uniform, sharp features in the final product mean that each chip can yield more usable circuits.

However, controlling a plasma-particularly at submicrometer levels-is not easy. The plasma gases used in semiconductor manufacturing are usually highly reactive ones such as chlorine and oxygen. The interactions between these gases and the surface of the chamber walls, as well as the material being etched, are complex and not entirely understood. For the manufacturing process to be most efficient, the ion energy of the plasma must be carefully controlled, and the flux of plasma ions onto surfaces must be uniform.

Until now, designing plasma-aided manufacturing tools has been done mostly by trial and error. But as integrated circuits began to incorporate smaller and smaller features-some now approach the nanometer scale-a more rigorous process for designing tools was needed.

\section{Designing the Best Plasma Tools Possible}

INDUCT95 models plasma chemistry and transport, keeping track of the average density, temperature, and velocity of each

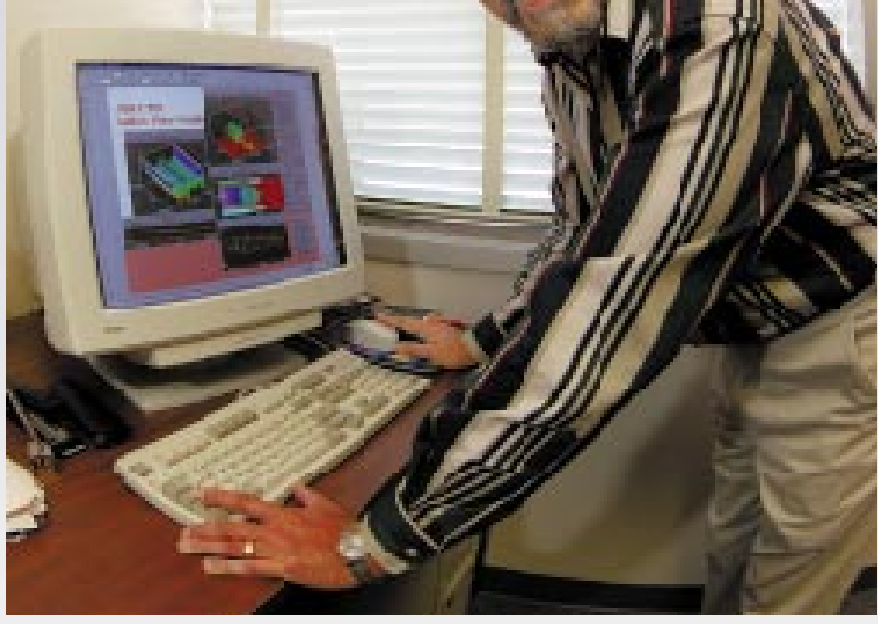

Figure 1. Livermore physicist Peter Vitello and INDUCT95, a computer-aided software simulation tool for plasma-assisted semiconductor manufacturing.

type of particle. The code provides numerical solutions for how the plasma evolves over space and time-in terms of its density, velocity, temperature, and electric field-and analyzes the plasma in two dimensions. It is unique in its robustness, speed, and key modeling capabilities.

The code also models the chemical reactions of the plasma with the neutral gas. In fact, INDUCT95 examines all reactions between all the types of particles in the bulk of the plasma system and on all the surfaces involved.

INDUCT95 takes the fluid modeling approach to the plasma. "Treating the plasma as a fluid of ions and electrons is very accurate for the conditions used in commercial plasma-aided manufacturing systems," says Vitello. "The fluid approach to computation is hundreds of times faster and more stable than a treatment of the plasma as a system of discrete particles." The approach allows many physical processes to be included, yet the code can often be run in a matter of hours. Tight integration of all physical processes results in unmatched code stability.

As Vitello points out, the chemistry in the plasma reactor chamber is extremely complex. Dozens of different types of neutral and ion species lead to hundreds of rate equations (i.e., two-dimensional, time-dependent, chemical equations). INDUCT95 was designed to excel in this environment. 


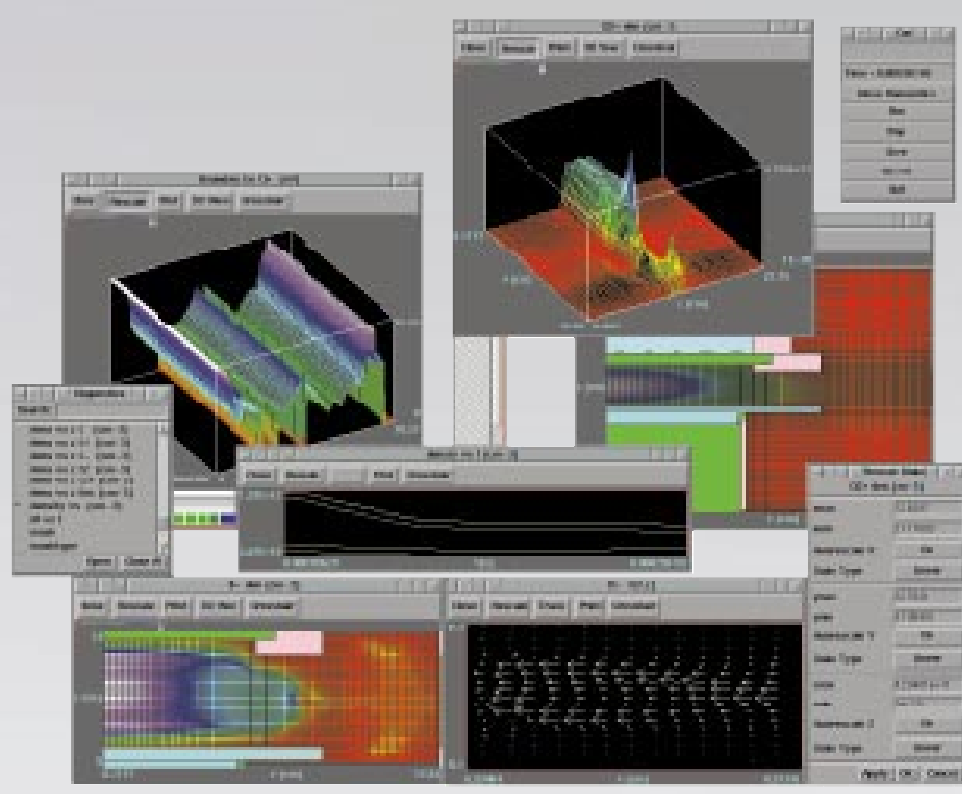

Figure 2. Facilitated by pull-down menus and push-button commands, INDUCT95 graphs plasma variables such as chemical reactions, density, and velocity.

"Sometimes, the other codes-which are designed for academic research and not for extremely complex situationscannot complete the computation," Vitello explains. "For INDUCT95, I had this application in mind from the start. I was also concerned with quality control from day one. As a result, INDUCT95 runs fast and efficiently from a basic desktop PC and requires no special computer equipment" (Figure 2).

"A reactor chamber is made of different materials-stainless steel, aluminum, quartz for the window, and so on," says Vitello. "The plasma gases react chemically with these materials at the surfaces. Etch rates depend on the surface material of the chamber and the chip. The microstructures often require geometric structures composed of different material types. INDUCT95 models these complicated systems easily, reducing the amount of memory and run time needed."

In addition, INDUCT95 is the only plasma reactor code that successfully models applied, time-dependent high-voltage effects in complex geometries and effectively models highdensity electronegative plasmas.

\section{Designing Plasma Electrodes for High Voltages}

Accurately modeling high voltages is important to the design of the electrodes that apply these voltages to the plasma. This voltage controls two critical aspects of the plasma: shaping the plasma's density in space and accelerating the ions onto the etching surfaces.

Manufacturers want a semiconductor device that is etched uniformly or that has a uniform deposit across the surface. To achieve this, the shape, position, frequency, and voltage of each electrode must be finely controlled.
"For example," said Vitello, "the use of multiple electrodes with wildly differing properties may lead to great variations in the plasma behavior, which can degrade the final product.

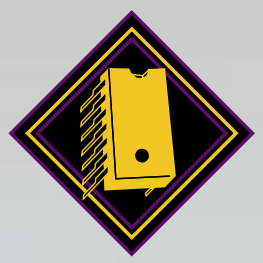
These conditions are very difficult to accurately follow in semiconductor processing. INDUCT95 is the only software capable of modeling this environment."

\section{Modeling Electronegative Plasmas}

Highly reactive electronegative plasmas-plasmas containing a large fraction of negative ions-are commonly used in plasmaaided manufacturing. At high plasma densities and low neutral gas pressures, which are the design goals of new plasma processing equipment, the scattering of ions with ions dominates the scattering of ions with neutral gas particles. The ion-ion scattering thus governs behavior of the plasma current.

"No one else has considered the problem of ion-ion coupling in this environment," said Vitello. "Most computer-aided design codes for this particular application make simple assumptions about the interactions. INDUCT95 is the only code that has successfully modeled the turbulence and instabilities of ion-ion coupling in the plasma reactor."

\section{Other Ventures for Plasma Modeling}

The code's applications at Livermore extend beyond commercial uses. For example, INDUCT95 simulations will provide engineers with a better understanding of the plasma discharge process so they can improve the design of a unique high-voltage insulator for Livermore's Advanced Hydrotest Facility.

INDUCT95 can be applied to areas outside the semiconductor industry as well. The code can model a wide range of plasma discharges, including plasma sources for flat panel displays, glow discharges (such as those in fluorescent lamps), and filament streamer propagation used in hazardous waste treatments.

"The modeling software has matured and can make a significant contribution to industry," says Vitello. "No longer does a plasma tool designer have to design "by guess or by golly.' This code allows us to explore the complex chemistry and physics of these little understood, but important, processes. In a sense, INDUCT95 provides another window into the physics of plasmas."

-Ann Parker

Key Words: computer-aided design, INDUCT95, plasma, plasma simulation, semiconductor.

For further information contact Peter Vitello (925) 422-0079 (vitello@IInl.gov). 


\section{Patents}

Patent issued to

Chi-Yung Fu

Loren I. Petrich
Patent title, number, and date of issue

Selective Document Image Data Compression Technique

U.S. Patent $5,754,697$

May 19, 1998

Summary of disclosure

A method of storing information from filled-in form documents by extracting the filled-in information in the foreground from form information in the background. This method is particularly useful for storing information on the front of checks. The method includes extracting the filled-in information from the form information, converting the filled-in information to a two-color format, and compressing the filled-in information. The filled-in information is presented in a digitized image array of pixels, each having a color value and position in the array.

J ames H. McQuaid Anthony D. Lavietes
Ambient Temperature Cadmium Zinc Telluride Radiation Detector and Amplifier Circuit

U.S. Patent $5,757,227$

May 26, 1998
A low-noise, low-power-consumption, compact, ambienttemperature signal amplifier for a cadmium-zinc-telluride radiation detector that allows efficient, high-resolution detection; isotopic analysis; and identification of radionuclides in the field. The circuit stages of this amplifier use integrated circuit amplifiers, rather than discrete components, and include a very-low-noise, highbandwidth, dual-part preamplification stage; an amplification stage; and a filter stage. By using integrated circuits and a single 12-volt power supply and ground, this amplifier saves significant power; is well suited for prolonged, portable, in-field use; and does not require a heavy, bulky power supply.

\section{Short Range, Ultra-wideband Radar with High Resolution Swept Range Gate}

U.S. Patent $5,757,320$

May 26, 1998
A radar range finder and hidden-object locator based on ultrawideband radar with a high-resolution swept range gate. The device generates an equivalent time-amplitude scan with a typical range of 4 inches to 20 feet and an analog range resolution as limited by a jitter of about 0.01 inch. A differential sampling receiver is used to effectively eliminate ringing and other aberrations induced in the receiver by the near proximity of the transmit antenna. As a result, a background subtraction is not needed, thus simplifying the circuitry while improving performance.

An interface structure for hub and mass attachment in flywheel rotors. The interface structure efficiently transmits high radial compression forces and withstands both large circumferential elongation and local stresses generated by mass-loading and hub attachments. The interface structure is composed of high-strength fiber, such as glass and carbon, woven into an angle pattern that is about 45 degrees with respect to the rotor axis. The woven fiber is bonded by a ductile matrix material that is compatible with and adheres to the rotor material. This woven fiber is able to elongate in the circumferential direction to match the rotor growth during spinning.

\section{A method for forming patterned buried components, such as} collectors, sources, and drains, in silicon-on-insulator devices. The method is carried out by epitaxially growing a suitable sequence of single- or multiple-etch stop layers (ending with a thin silicon layer) on a silicon substrate, masking the silicon such that the desired pattern is exposed, introducing and activating dopant in the thin silicon layer to form doped regions, and then bonding the silicon layer to an insulator substrate and removing the silicon substrate. The method also involves forming electrical contact regions in the thin silicon layer for the buried collectors. 


\section{Patents}

Patent issued to

Daniel M. Makowiecki

J ohn A. Kerns

Kenneth L. Blaedel

. Colella

Pete J. Davis

Robert S. J untz
Patent title, number, and date of issue

Precision Replenishable Grinding Tool and Manufacturing Process

U.S. Patent $5,762,660$

J une 9, 1998
Summary of disclosure

A reusable grinding tool consisting of a replaceable single layer of abrasive particles bonded to a precisely configured tool substrate and a process for manufacturing the grinding tool. The manufacturing process involves coating the ceramic or metal tool substrate with layers of metal, such as titanium, copper, and titanium by vapor deposition; applying diamond or cubic boron nitride abrasive particles to the coated surface by a slurry technique; and brazing the abrasive particles to the tool substrate by alloying the metal layers. The precision control of the composition and thickness of the metal layers enables the bonding of a single layer or several layers of micrometer-size abrasive particles to the tool surface. Incorporation of an easily dissolved metal layer in the composition allows the removal and replacement of the abrasive particles.
Steven Falabella

\section{Amorphous Diamond Films}

U.S. Patent $5,763,087$

J une 9, 1998
A method for coating a substrate with an amorphous diamond film by biasing the substrate to be coated and depositing carbon ions on it under controlled temperature conditions. The method significantly reduces the intrinsic stress on the film and improves adhesion.
Thomas E. McEwan

\section{Body Monitoring and Imaging Apparatus and Method}

U.S. Patent 5,766,208

J une 16, 1998
A nonacoustic pulse-echo radar monitor is employed in the repetitive mode, whereby a large number of reflected pulses are averaged to produce a voltage that modulates an audio oscillator to produce a tone that corresponds to the heart's motion. The antenna used in this monitor generally comprises two flat copper foils, thus permitting the antenna to be housed in a substantially flat housing. The monitor converts the detected voltage to an audible signal with both amplitude modulation and Doppler effect. It also uses a dual time constant to reduce the effect of gross sensor-to-surface movement. The monitor detects the movement of one or more internal body parts (heart, lungs, arteries, vocal chords) and includes a pulse generator for simultaneously inputting a sequence of pulses to a transmit path and a grating path. The device has applications in medicine and rescue operations.

\section{Awards}

Physicist Steve Payne received a 1998 Excellence in Fusion Engineering Award by Fusion Power Associates at a recent meeting of the Department of E nergy F usion Energy Advisory Committee in Germantown, Maryland. The award (one of two presented this year) is given "to recognize and encourage individuals in the early part of their careers who have shown both outstanding technical accomplishment and potential to be exceptionally influential leaders in the fusion field."

A Livermore employee since 1985 and an associate program leader in the Laser Programs Directorate, Payne was cited for developing a new fusion-research laser that uses laser diode arrays in place of flashlamps, laser crystals instead of glass, and near-sonic gas coolant. The award notes that $P$ ayne has invented new laser materials, studied the survivability of materials under intense radiation, guided an extensive power plant study, and been instrumental in organizing national and international collaborations.

Livermore physicists Gilbert Collins, Peter Celliers, Luiz Da Silva, and Robert Cauble have been selected by the American Physical Society to receive its 1998 Award for Excellence in Plasma Physics Research. The four scientists were commended for a series of experiments they conducted on the Nova laser to measure the properties of hydrogen. They were cited for an exquisite series of experiments using high-intensity lasers to measure the high-pressure properties of hydrogen across the molecular insulator to monatomic metal transition. The purpose of the year-long set of experiments was to study the properties of hydrogen under high pressure. 
(Continued from p. 2.)

\section{B-Factory achieves major milestone}

The B-Factory at the Stanford Linear Accelerator Center (SLAC) in Menlo Park, California, achieved a major milestone on July 23, 1998, when high-energy (electron) and low-energy (positron) particle beams were brought into collision for the first time in the Positron-Electron Project-II accelerator. PEP-II is a key component of the B-Factory, a $\$ 300$-million expansion of the linear accelerator at SLAC. The milestone was accomplished two months ahead of schedule, resulting in the completion of the PEP-II phase of the project on cost and ahead of schedule.

The B-Factory project is a collaboration of SLAC and Lawrence Livermore and Lawrence Berkeley national laboratories. The B-Factory is a high-energy particle-physics research facility, which will provide important clues about what happened moments after the Big Bang to account for the preponderance of matter over antimatter in the universe.

For more information on the B-Factory, see $S \& T R$, January/February 1997, pp. 4-13.

Contact: Karl Van Bibber (925) 423-8949 (vanbibber1@IInl.gov).

\section{New model may explain gamma-ray bursts}

Scientists from the Laboratory and Notre Dame University have announced a new model that may, for the first time, explain a large class of gamma-ray bursts, one of the universe's most unyielding mysteries.

Gamma-ray bursts are tremendous releases of energy in the distant cosmos viewed daily by satellites in Earth orbit as brilliant flashes of gamma-ray light. Scientists have long theorized that the gamma-ray bursts may result from the collision of twin burned-out, collapsed stars, known as binary neutron star systems, that orbit around each other hundreds of times per second. But the difficulty is explaining how the tremendous energy from a binary star collision translates into a gamma-ray burst.

Livermore scientist Jay D. Salmonson and Grant J. Mathews of Notre Dame University recently presented to the American Astronomical Society a new hypothesis to explain gamma-ray bursts, based on studies by Mathews and Livermore's James R. Wilson, that occurs not from the collision of the neutron stars but moments before it. Using computer simulations of neutron binary star systems that incorporate Einstein's general theory of relativity, Mathews and Wilson found that the stars are observed to be compressed several seconds before merging. The general relativistic gravitational effect of two neutron stars rapidly revolving around each other squeezes and heats both stars. The squeezing and heating cause the stars to radiate a staggering number of elusive subatomic particles called neutrinos, a small fraction of which collide, creating innumerable electron-positron pairs.

A superhot cloud of these pairs then expands off the surfaces of the neutron stars and rapidly accelerates into space. In the midst of this expanding fireball, the electrons and positrons in turn collide to create gamma-ray photons, and the massive conversion of electrons and positrons to photons produces the gamma-ray burst.

"We're theorizing that the gamma-ray burst is not the observable effect from the collision of the in-spiraling neutron binaries, but the result of heating and the subsequent neutrinoto-photon radiation process that occurs in a few brief seconds before such a collision," said Salmonson.

Contact: J ames R. Wilson (925) 422-1659 (wilson33@llnl.gov) or J ay D. Salmonson (925) 423-0752 (salmonson1@IInl.gov). 


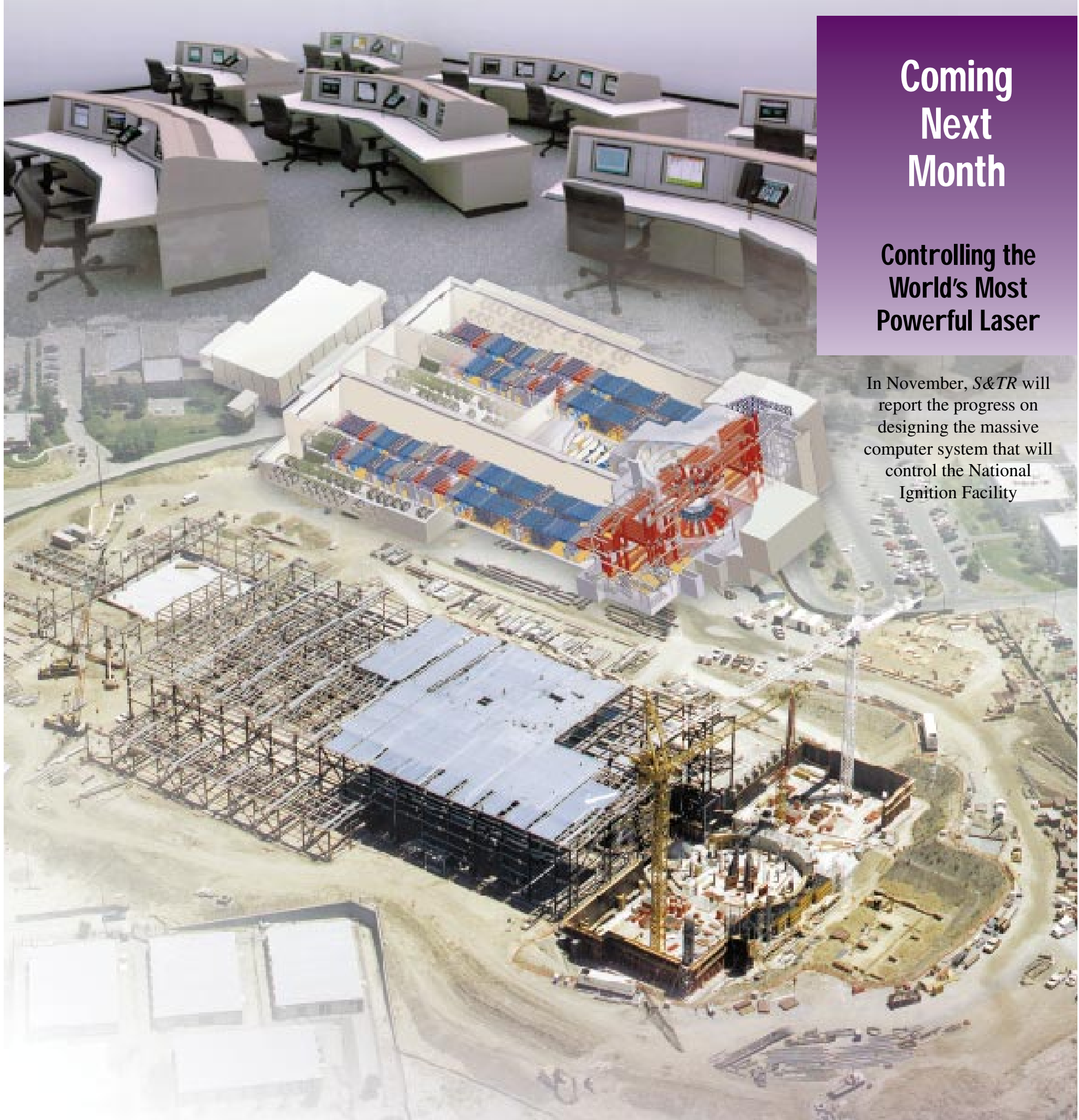

\section{Also in November}

- Basic Science Projects for Environmental Management

- Livermore's Contribution to the Discovery of a Kidney Disorder Gene

- Engineering Advanced Materials with the Help of Secondary Ion Mass Spectrometry 